Original Paper http://ajol.info/index.php/ijbcs http://indexmedicus.afro.who.int

\title{
Development and validation of a UV-Visible method for the determination of the active principle Efavirenz in tablets
}

\author{
Nassifatou Koko TITTIKPINA ${ }^{1,2,3^{*}}$, Thierno Mouhamed WANE ${ }^{2}$, Diery DIOUF ${ }^{1,5}$, \\ Khadidiatou THIAM ${ }^{2}$, Amadou DIOP ${ }^{2}$, Djibril FALL ${ }^{1,4}$, Yerim Mbagnick DIOP ${ }^{1,2,3}$ and \\ Serigne Omar SARR ${ }^{1,2}$ \\ ${ }^{1}$ Laboratoire National de Contrôle des Médicaments, Dakar-Plateau, Dakar, Sénégal. \\ ${ }^{2}$ Laboratoire de Chimie Organique et Thérapeutique, Faculté de Médecine, de Pharmacie et d'Odontologie, \\ Université Cheikh Anta Diop de Dakar, BP 5005, Dakar-Fann, Sénégal. \\ ${ }^{3}$ Laboratoire de photochimie et d'analyse, Département de Chimie, Faculté des Sciences et Techniques, Université \\ Cheikh Anta Diop de Dakar, BP 5005, Dakar-Fann, Sénégal. \\ *Corresponding author; E-mail: knassifa@yahoo.fr; Tel: $0022891838783 / 0022891008380$.
}

\section{ACKNOWLEDGEMENTS}

We acknowledge the Pierre Fabre Foundation for its Postdoctoral fellowship to NKT.

\begin{abstract}
Methods proposed by pharmacopeias to control the quality of Efavirenz, an antiretroviral drug used in the treatment of AIDS are based on expensive equipment which are most of the time not available in African countries. To solve this issue, using UV-visible spectrophotometry, a cheap and easy-to-use device available in many laboratories on the African continent; a sensitive, reliable, simple and rapid method has been validated for the determination of the active substance Evafirenz in Efavirenz tablets, to control their quality by checking its dosage. The accuracy profile approach was adopted. The response function gave a correlation coefficient $\mathrm{R}^{2}=0.9987$. The detection and quantification limits were $0.15625 \mu \mathrm{g} / \mathrm{mL}$ and $0.515625 \mu \mathrm{g} / \mathrm{mL}$, respectively. The acceptability limit has been set at $15 \%$. The tolerance limits for the different concentration levels $(80,100$ and $120 \%)$ are represented respectively as follows: lower limits $86.2 ; 90.3$ and $96.1 \%$; upper limits $100.2 ; 106.3$ and $113.7 \%$. The tolerance limits are within the acceptability limits for values around $100 \%$ concentration $(7 \mu \mathrm{g} / \mathrm{mL})$. Therefore, the method was declared valid and reliable for the analysis of Efavirenz in Efavirenz tablets and could routinely be used in laboratories for the quality control of EFAVIRENZ drug.
\end{abstract}

(C) 2020 International Formulae Group. All rights reserved.

Keywords: Efavirenz, accuracy profile, spectrophotometry, pharmaceutical formulation.

\section{INTRODUCTION}

A pharmaceutical product is defined in the Public Health Code of Togo as 'any substance or composition presented as possessing preventative properties that are curative for human or animal diseases' (CSP,
2019). This definition of the drug is literally endangered in developing countries where $10 \%$ of medicines are counterfeit or falsified (WHO, 2017). Indeed, this counterfeiting or falsification no longer allows concerned to achieve its curative or preventive function on human 
diseases. The counterfeit or falsified medicine could then become a poison for humans instead of fulfilling its beneficial role for health. One example of pharmaceutical product becoming poison is, an unfortunate event that happened in Pakistan in 2013: 60 adults died after consumption of cough syrup produced by a laboratory in India. The cough syrup labelled to contain dextromethorphan and usual anticough ingredients in syrup, was in fact made of levomethorphan, a powerful drug, five times stronger than morphine (WHO, 2017). This event is one of many other events recorded and mostly unrecorded happening worldwide in different countries, especially the developing ones with Africa being home to the highest number of those events.

Indeed, from 2013 to 2018, the World Health Organization (WHO) has received 1500 reports of counterfeit drugs from which $42 \%$ come from Africa. The African market is considered an easy target by counterfeiters because of the lack of strong regulatory authorities and the inexistence of quality control facilities. And every year, in each one of the countries located in Sub-Saharan Africa, at least one alert is issued on the circulation of falsified drugs. For example, recently, on the $28^{\text {th }}$ March 2019, the WHO has issued an alert on falsified meningitis vaccines circulating in Niger (WHO, 2019). In addition, products used against infectious diseases are among the most falsified ones in Africa. Besides, there is an actual increase in the resistance of usual drugs against infectious diseases. Those combined situations have created a heavy burden on healthcare systems in African countries considering the fact that most of the time there is no quality control performed on the drugs and food entering and or present the market in those countries (Tittikpina, 2013; WHO, 2018; Maïwore et al., 2018; Djibrine et al., 2018; Diabaté et al., 2018; Ishaku et al., 2019). Medicines used against viral infections, caused by HIV-AIDS and hepatitis, are not an exception to this counterfeit.
One of those medicines, Efavirenz, is of almost importance because of its use to treat HIV-AIDS in 3 years old children and also its combination with other anti-HIV-AIDS products to treat simultaneously AIDS and hepatitis B (Tibalinda et al., 2017; PNLS, 2019). An analytical method to perform the quality control of Efavirenz is consequently needed. Unfortunately, the existing method to achieve this objective uses equipment that is not generally available in laboratories in African countries. Indeed, the method proposed by the American pharmacopoeia uses not only HPLC (heavy and very expensive equipment) but also an LH column (the medium is a hydroxypropylated dextran that has been crosslinked to yield a polysaccharide network) compared to a $\mathrm{C} 18$ column (which is easily available in many laboratories where HPLC exists) (USP, 2013). Given the situation in many African countries, there is an urgent need to develop a feasible method, easy and inexpensive, that uses readily available equipment. This study aims to fill this gap by developing a method using a UV-Vis spectrophotometer, a cheap and easy-to-use device available in many laboratories on the African continent and in many other low- and middle-income countries around the world. The method validated will help control the quality of Efavirenz drugs by checking the concentration of the active principle Efavirenz in pharmaceutical tablets.

\section{MATERIALS AND METHODS}

\section{Materials}

\section{Reagents}

Efavirenz tablets (Efavirenz Macleods $®$ tablets), Efavirenz standard (United States Pharmacopeia) and HPLC grade ethanol for the dissolution of Efavirenz were obtained from the Senegalese National Medicines Control laboratory (LNCM, 39 Avenue Pasteur, Dakar).

Ultrapure water was obtained from a Milli-Q® water purification system (Millipore, Molsheim, France). 


\section{Apparatus}

A JASCO UV/Vis double beam spectrophotometer (model V-570) with $1 \mathrm{~cm}$ quartz cells was used for all spectral measurements.

\section{Methods}

\section{Preparation of solutions}

Efavirenz Macleods ${ }^{\circledR}$ tablets were powdered. The appropriate amounts were weighed and dissolved in ethanol to obtain concentrations ranging from $12 \mu \mathrm{g} / \mathrm{mL}$ to 0.625 $\mu \mathrm{g} / \mathrm{mL}$ of the active ingredient Efavirenz. Two different batches of Efavirenz Macleods ${ }^{\circledR}$ tablets were used to prepare two independent solutions as described above.

Standard Efavirenz (USP) was prepared by dissolving the required amount in ethanol to obtain concentrations ranging from $12 \mu \mathrm{g} / \mathrm{mL}$ to $0.625 \mu \mathrm{g} / \mathrm{mL}$ of efavirenz.

\section{Wavelength selection}

Two $10 \mu \mathrm{g} / \mathrm{mL}$ solutions of Efavirenz tablets from two different batches and a 10 $\mu \mathrm{g} / \mathrm{mL}$ solution of standard Efavirenz were prepared. The absorption spectra of the three solutions were recorded in the 200-800 nm range. Three absorption maxima were observed at 207, 251 and $301 \mathrm{~nm}$. The wavelength at 251 $\mathrm{nm}$ was chosen because it provides the maximum absorption (between 0.5 and 1) and also because it is not too close to the visible (Figure 1).

\section{Validation of the method}

The method was validated by evaluating the following parameters: linearity and range, accuracy, precision, selectivity, limit of detection (LOD), limit of quantification (LOQ) as specified in the International Conference on Harmonisation protocol (ICH, 2005). The method has been validated using the accuracy profile, a fitness-to-purpose approach of the validation. It is based on a graphical decisionmaking tool, called the accuracy profile. Using measurements collected under reproducibility or intermediate precision conditions, it allows computing an interval where a known proportion of future measurements will be located. When comparing this interval to an acceptability interval defined by the result end-user, it is possible to simply decide whether a method is valid or not (Feinberg, 2007; Marlet and Lognay 2010; Smith et al., 2014; Mottier et al., 2016; Frampas et al., 2018; Ibrahim et al., 2020).

Linearity and range: Efavirenz solutions with concentrations of $10,7,5,3.5,2.5$ and 1.25 $\mu \mathrm{g} / \mathrm{mL}$ were prepared. The solutions were scanned using a spectrophotometer in the 200$400 \mathrm{~nm}$ UV range. The Efavirenz absorbance was recorded at $251 \mathrm{~nm}$. The calibration curve was constructed as a function of concentration and absorbance.

Intra-day and inter-day precision studies: intra-day precision (repeatability) was performed at $5.6,7$ and $8.4 \mu \mathrm{g} / \mathrm{mL}$ with 3 replicates. Interday precision (intermediate precision) was performed at the same concentrations with 3 replicates and on 3 consecutive days. The relative standard deviation (RSDs) values (RSDR: Relative Standard Deviation of the daily Repeatability and RSDIP: Relative Standard Deviation of the Intermediate Precision) were calculated as follows:

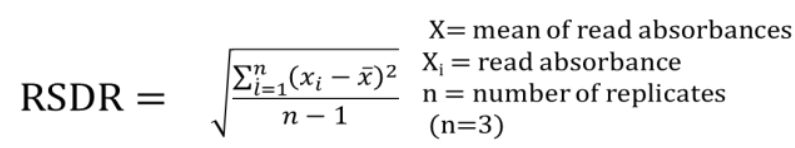

And the RSDIP was obtained with the following formula:

$$
\text { RSDIP }=\sqrt{\frac{1}{k} \sum_{j=1}^{k} R S D R_{j}^{2}} \quad \begin{aligned}
& \mathrm{RSDR}_{\mathrm{j}}=\text { Relative Standard Deviation of the daily Repetability } \\
& \mathrm{k}=\text { number of days }(\mathrm{k}=3)
\end{aligned}
$$

- Trueness (recovery) was determined by comparing the concentrations really obtained with the theoretically expected concentrations (R). To achieve it, during the studies performed for intraday and inter-day precision studies, a calibration graph was established each day and the experimental concentrations obtained on each day, 
for each concentration and every repetition, was calculated using this curve.

Considering the curve with the equation: $y=a \boldsymbol{x}$ $+b$, were $\mathrm{x}$ is equal to $\mathrm{R}$.

$$
\mathrm{R}=\left(\frac{y-b}{a}\right) \times 100 \mathrm{y}=\text { measured absorbance }
$$

The trueness is obtained by the following equation:

Trueness $=\frac{\sum_{j=1}^{n_{1}} R_{1} d}{n_{1}} \quad \begin{aligned} & \mathrm{R}_{1 \mathrm{~d}}=\text { recovery obtained on a single replicate of } \\ & \text { a concentration } \\ & \mathrm{n}_{1}=\text { number of days }\left(\mathrm{n}_{1}=3\right)\end{aligned}$

- Selectivity: selectivity was evaluated during wavelength selection by recording the spectra of the standard solution and the two solutions obtained from two different batches (working solutions).

Limit of detection (LOD) and limit of quantification (LOQ): the LOD was determined by serial dilution of working solutions to obtain the lowest concentration after which no distinction could be visually made between the recorded absorbance due to the compound present in the solution and the spectrophotometer background noise. The LOQ was determined using the ICH guidelines which state LOQ to be equal to 3.3 times the LOD.

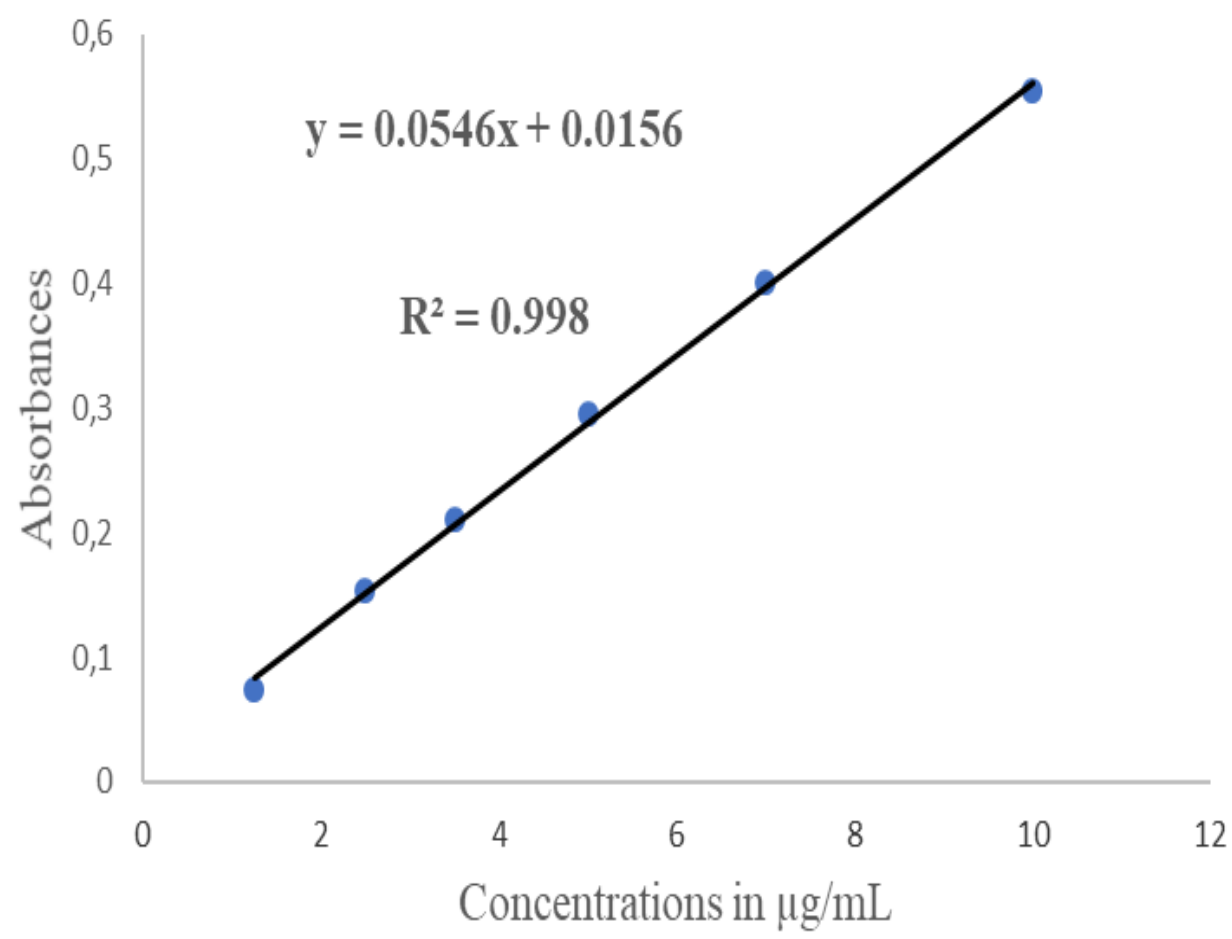

Figure 1: Calibration curve graph obtained with different concentrations of Efavirenz. 


\section{RESULTS}

Linearity and range; intra-day and inter-day precision studies and trueness; limit of detection (LOD) and limit of quantification (LOQ)

Linearity was obtained over a concentration range of $1.25 \mu \mathrm{g} / \mathrm{mL}$ to $10 \mu \mathrm{g} / \mathrm{mL}$ with a correlation coefficient $\left(\mathrm{R}^{2}\right)$ of 0.9987 (Table 1, Figure 1). RSDs values for intra-day and inter-day precision studies were belonging respectively to the following ranges: $0.7 \%$ to $3.5 \%$ and $2.9 \%$ to $3.6 \%$ (Table 2 ) and recoveries obtained were ranging from $98.2 \%$ to $112.9 \%$ (Table 3). Finally, the LOD and LOQ recorded are respectively $0.15625 \mu \mathrm{g} / \mathrm{mL}$ and 0.515625 $\mu \mathrm{g} / \mathrm{mL}$.

\section{Selectivity}

By recording the graphs obtained with the three prepared solutions, it could easily be noticed that the graphs almost fit in each other (Figure 2). It could therefore be concluded that the method is selective. Besides, the maxima obtained at $251 \mathrm{~nm}$ are less than 1 (the norm). Working at $251 \mathrm{~nm}$ is consequently the wavelength of choice for this method.

\section{Validation of the method}

Considering the different norms used to perform the validation, the degree of freedom and the risk were established at 6 and 5\%, respectively. The inverse Student Test (t) calculated computed with those parameters gave a value equal to 2.45 . The confidence interval (CI), the upper bound (UB) and lower bound (LB) of the accuracy profile of the method were calculated. The acceptance limit $\boldsymbol{\beta}$ was set at $15 \%$ allowing the computation of the superior and inferior limits of the accuracy profile. The values obtained for the different parameters computed for the establishment of the accuracy profile are summarized in Table 4 and the graph obtained is reported in Figure 3. From the accuracy profile (Figure 3), it could be concluded that the validation of the method could be set at $100 \%$ concentration of the analyte or tablet to be investigated $(7 \mu \mathrm{g} / \mathrm{mL}$ in this study) and with values not too far away from this concentration. Indeed, this concentration and the values that are close to it, lie perfectly within the limits of the graph.

Table 1: Absorbances recorded for different concentrations of Efavirenz when establishing daily calibration graphs.

\begin{tabular}{ll}
\hline Concentration in $\boldsymbol{\mu g} / \mathbf{m L}$ & Absorbance \\
\hline 10 & 0.55477679 \\
7 & 0.40154345 \\
5 & 0.29472345 \\
3.5 & 0.21136679 \\
2.5 & 0.15301679 \\
1.25 & 0.07462345 \\
\hline
\end{tabular}

Table 2: Summary of RSDs evaluated for intra-day and inter-day precision studies RSD : Relative Standard Deviation. Concentration : percentage (\%) of $7 \mu \mathrm{g} / \mathrm{mL}$.

\begin{tabular}{llll}
\hline Concentrations & $\mathbf{8 0 \%}$ & $\mathbf{1 0 0 \%}$ & $\mathbf{1 2 0 \%}$ \\
\hline RSD inter-day precision & $3.5 \%$ & $0.7 \%$ & $2.9 \%$ \\
RSD intra-day precision & $3.6 \%$ & $3.3 \%$ & $2.9 \%$ \\
\hline
\end{tabular}


Table 3 : Recoveries Concentration : percentage (\%) of $7 \mu \mathrm{g} / \mathrm{mL}$.

\begin{tabular}{llll}
\hline Concentration (\%) & Replicate 1 & Replicate 2 & Replicate 3 \\
\hline 80 & 108.8 & 110.4 & 111.3 \\
80 & 103.2 & 104.1 & 112.5 \\
80 & 112.9 & 110.3 & 112.4 \\
100 & 109.1 & 113.4 & 107.8 \\
100 & 108.7 & 112.5 & 106.7 \\
100 & 109.4 & 113.4 & 105.7 \\
120 & 107.2 & 100.6 & 104.4 \\
120 & 101.5 & 100.9 & 98.2 \\
120 & 102,1 & 100.9 & 105.4 \\
\hline
\end{tabular}

1,2

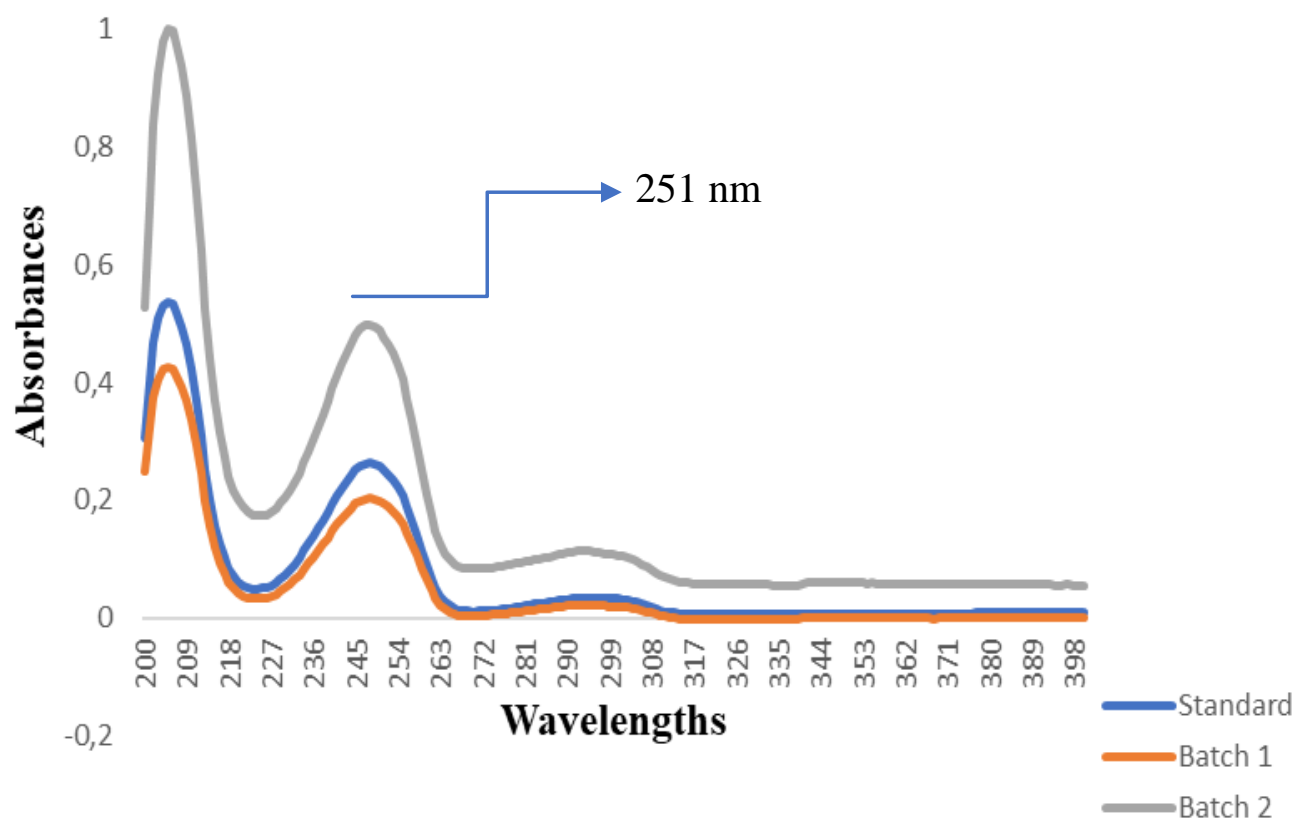

Figure 2: Efavirenz UV-Visible absorption spectra at $10 \mu \mathrm{g} / \mathrm{mL}$. 
Table 4: Summary of the accuracy profile.

\begin{tabular}{lllllllll}
\hline Conc & Accuracy & RSDR & RSDIP & CI & UB & LB & SL & IL \\
\hline $80 \%$ & $104.9 \%$ & $3.5 \%$ & $3.6 \%$ & $8.8 \%$ & $113.7 \%$ & $96.1 \%$ & $115 \%$ & $85 \%$ \\
$100 \%$ & $98.3 \%$ & $0.7 \%$ & $3.3 \%$ & $8.0 \%$ & $106.3 \%$ & $90.3 \%$ & $115 \%$ & $85 \%$ \\
$120 \%$ & $93.2 \%$ & $2.9 \%$ & $2.9 \%$ & $7.0 \%$ & $100.2 \%$ & $86.2 \%$ & $115 \%$ & $85 \%$ \\
\hline
\end{tabular}

Conc: concentration; RSDR: Relative Standard Deviation for Repeatability; RSDIP: Relative Standard Deviation for Intermediate Precision; CI: Confidence Interval; UB: Upper Bound; LB: Lower Bound; SL: Superior Limit, IL: Inferior Limit. $\mathrm{CI}=\mathrm{RSDIP} \times \mathbf{t} ; \mathrm{UB}=\mathrm{Justesse}+\mathrm{CI} ; \mathrm{LB}=$ Accuracy $-\mathrm{CI} ; \mathrm{SL}=100+\beta ; \mathrm{IL}=100-\beta$.

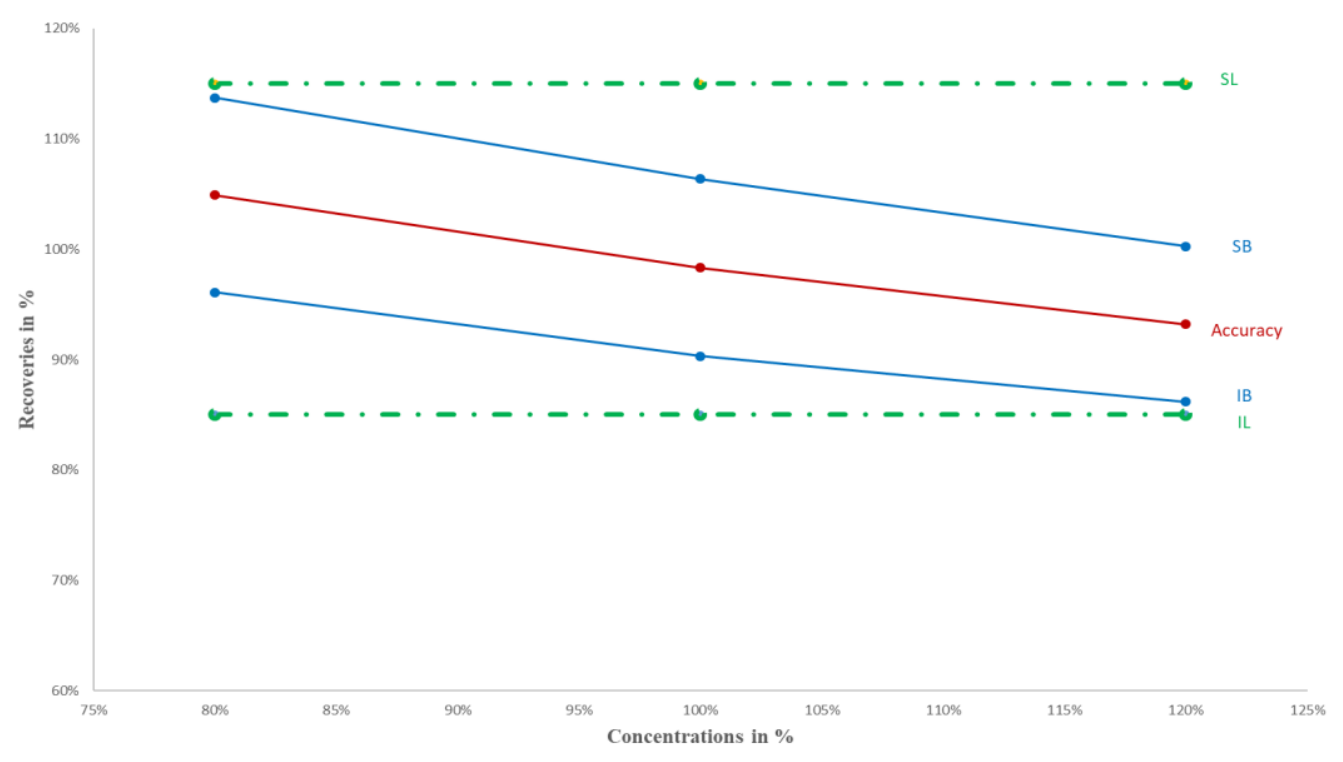

Figure 3: Method based on accuracy profile.

SL: superior limit, IL: inferior limit; SB: superior bond, IB: inferior bond.

\section{DISCUSSION}

The correlation coefficient found in this study concerning the linearity, respects the norm (very close to $1 ; \mathrm{R}^{2}=0.9987$ ) and is almost equal to that found in a study by Pathade (et al., 2017) $\left(R^{2}=0.999\right)$ on the development and validation of the UV spectrophotometric method for the determination and stability study of sitagliptin phosphate in bulk and tablet form. The result is also similar to the ones recorded by Montgomery (et al., 2001) (greater than 0.9999) on the development and validation of a reversephase HPLC method for analysis of Efavirenz and its related substances in the drug substance and in a capsule formulation. The fact that the results obtained in previous studies using an
HPLC, are similar to the ones obtained in the present study using an UV-spectrophotometric method, suggests the present method to be suitable for the determination of Efavirenz in tablets. The value is also similar to that recorded by a previous study by Djiambeu (2015), realized in the same laboratory (0.9993) on the validation of a UV-Visible spectrophotometric method for the determination of reformulated chlorpheniramin maleate. RSDs values obtained for intra-day and inter-day precision studies were also similar to those of Djiambeu (2015): $1.5 \%$ to $3.1 \%$ for intra-day precision and $2.1 \%$ to $3.1 \%$ for inter-day precision studies. They are also similar to the results of Safari (et al., 2019) on the solid-phase extraction combined with 
dispersive liquid-liquid microextraction HPLC$\mathrm{UV}$ as a sensitive and efficient method for the extraction, pre-concentration and simultaneous determination of the antiretroviral drugs Nevirapine, Efavirenz and Nelfinavir in pharmaceutical formulations and biological samples. Indeed, those authors in their work have found intra-day and inter-day precision (RSD in \%) in the range of $2.2-4.2 \%$ and $3.1-$ $5.2 \%$, respectively. Specifically, the intra-day and inter-day precision found in their work for Efavirenz were respectively $3.8 \%$ to $4.6 \%$ and are much higher to the ones obtained in the present study. Consequently, those results confirm the fact that UV-visible spectrophotometry allows to obtain results comparable or even better than those obtained when using a high-performance liquid chromatography method.

Recoveries values obtained in this study (98.2\% to $112.9 \%$ ) were similar to the ones obtained by Montgomery (et al, 2001) and Safari (et al., 2019) with mean recoveries of $99 \%$ for the first study and $95 \%$ to $100.5 \%$ for the second one. Those values are high in comparison to a different work published by Sarr (et al, 2016); on the development and validation of an electrophoresis method for quality assessment of metronidazole-based drugs where, values ranging from $94.7 \%$ to $100 \%$ were found. The high values obtained in this study might be due to the complex composition of Efavirenz tablets. Indeed, in addition to Efavirenz as active principle, Efavirenz tablets contain more than 20 other components. Besides, the LOD and LOQ recorded in this study are similar to those found by Pathade (et al., 2017); form $0.16 \mu \mathrm{g} / \mathrm{mL}$ and $0.45 \mu \mathrm{g} / \mathrm{mL}$. However, they are lower than those recorded in a study by Jain (et al., 2011); on the development and validation of the UV method for the determination of terbinafine hydrochloride in bulk and formulation, $0.42 \mu \mathrm{g}$ and $1.30 \mu \mathrm{g}$ respectively. The difference observed suggests the sensitivity of the method developed in the present work. In addition, the method was found to be selective at a wavelength of $251 \mathrm{~nm}$. This wavelength is very close to the one described in the US pharmacopeia (a $250 \mathrm{~nm}$ wavelength with a method based on High Performance Liquid Chromatography).

An acceptance limit $\boldsymbol{\beta}$ at $15 \%$, is far from current standards that set a limit of $5 \%$ to $10 \%$ for medicines. Indeed; Pinguet, 2015 stated that, the European Union Directive 5/318 / EEC stipulates a limit of $\pm 5 \%$, extended limits could only be justified by variations related to the production and the analytical procedure. The value at $15 \%$ is explained by the complexity of the drug studied. Indeed, Efavirenz Macleods ${ }^{\circledR}$ in its composition in addition to the active ingredient 'Efavirenz', is formulated with more than twenty other chemical compounds: excipients, binders, etc. Besides, during the validation process of the method tests have not been performed on a fabricated Efavirenz tablet in the laboratory, manufactured tablets have been used. A bias due to the composition of the tablets was therefore unavoidable, due to the fact that this composition is not controlled and no guarantee of the uniformity of the composition from one tablet to another one could be provided.

\section{Conclusion}

Falsified or counterfeit medicines are a real public health problem in developing countries where access to medicines is not easy for all segments of the population. Thus, it is important to ensure that the drugs available are of high quality. Quality control requires analytical methods, based on high-performance liquid chromatography and other very expensive equipment, which are not often available in the quality control laboratories of many countries on the African continent. It is therefore becoming necessary to seek cheaper but equally effective alternatives to the equipment usually required to ensure that medicines entering the territories and delivered to patients are of high quality. Efavirenz, used in HIV in children and coinfection with HIV and hepatitis B viruses, needs to have its quality checked because of the burden HIV and Hepatis B have on African healthcare systems especially those in West Africa. The method proposed in this study for its quality control, is based on UV-Visible spectrophotometry, a simple and effective method using an inexpensive device, compared 
to HPLC proposed by the American Pharmacopoeia. This method was validated at a $\beta$ limit of $15 \%$ and at concentrations around $100 \%$ ( $7 \mu \mathrm{g} / \mathrm{mL}$ in the present study). The recovery limits vary from $98 \%$ to $112 \%$ with an average repeatability of $2.4 \%$ and an average intermediate fidelity of $3.3 \%$. This method is simple to implement, does not consume large quantities of solvent and can be used in different laboratories for routine analysis.

\section{COMPETING INTERESTS}

The authors declare that they have no competing interests.

\section{AUTHORS CONTRIBUTIONS}

NKT performed the different experiments and wrote the manuscript. TMW helped with the statistics. DD helped with the running of the experiments with the UV-VIS spectrophotometry. KT corrected the first draft of the paper. SOS designed the research. SOS, YMD, DF and AD supervised the research. All the authors read, improved the paper and accepted its final version.

\section{ACKNOWLEDMENTS} advice.

We thank F Nepveu for the technical

\section{REFERENCES}

République Togolaise, 2009. Loi N²009/ 007 du 15 Mai 2009 portant Code de la Santé Publique de la République Togolaise. EDITOGO : Lomé.

Diabaté M, Dossou J, Nimaga D, Gbogouri AG, Amani GN. 2018. Etude diagnostique des pratiques de friture du thon du mets «Garba» consommé dans la ville d'Abidjan (Côte d'Ivoire). Int. J. Biol. Chem. Sci., 12 (3): 1333-1344. DOI: 10.4314/ijbcs.v12i3.21.

Djiambeu CLC. 2015. Validation d'une méthode de dosage sans extraction du maléate de chlorphénamine par Spectrophotométrie UV-VISIBLE au Laboratoire National de Contrôle des Médicaments. Master thesis, Université Cheick Anta Diop de Dakar, Dakar, p 54.
Djibrine MA, Tidjani A, Ngandolo BN, Nadlaou B, Barro N. 2018. Microbiological quality of some street foods in N'Djamena, Chad: case of sandwiches. Int. J. Biol. Chem. Sci., 12 (3): 1113-1122. DOI: 10.4314/ijbcs.v12i3.3.

Feinberg M. 2007 Validation of analytical methods based on accuracy profiles. $J$. Chromatogr. A, 1158: 174-183. DOI: 10.1016/j.chroma.2007.02.021.

Frampas C, Ney J, Coburn M, Augsburger M, Varlet V. 2018. Xenon detection in human blood: Analytical validation by accuracy profile and identification of critical storage parameters. J. Forensic Leg. Med., 58: 1419. DOI: 10.1016/j.jflm.2018.04.005.

Ibrahim AM, Hendawy HAM, Hassan WS, Shalaby A, El-sayed HM. 2019. Six Sigma quality approach for HPLC-UV method optimization. Microchem. J., 144: 303-308. DOI: 10.1016/j.microc.2018.09.023.

International Conference on Harmonization (ICH). 2005. Technical requirements for registration of pharmaceuticals for human use - Validation of analytical procedures: Text and methodology Q2(Rl). $\mathrm{ICH}$ : Geneva.

Ishaku SG, Bakare-Odunola TM, Musa A, Yakasai IA, Garba M, Adzu B. 2019. Evaluating the effect of artesunate on the pharmacokinetics of gliclazide in diabetic subjects. Int. J. Biol. Chem. Sci., 13(4): 2104-2111. DOI: 10.4314/ijbcs.v13i4.17.

Jain PS, Chaudhari AJ, Patel AS, Patel ZN, Patel DT. 2011. Development and validation of the UV-spectrophotometric method for determination of terbinafine hydrochloride in bulk and in formulation. Pharmaceuticals Methods, 2 (3): 198-202. DOI: 10.4103/2229-4708.90364.

Maïwore J, Baane MP, Ngoune LT, Fadila JA, Yero MY, Montet D. 2018. Qualité microbiologique et physico-chimique des laits fermentés consommés à Maroua (Cameroun). Int. J. Biol. Chem. Sci., 12 (3): 1234-1246. DOI: 10.4314/ijbcs.v12i3.13.

Marlet C, Lognay G. 2010. Development and validation by accuracy profile of a method for the analysis of monoterpenes in indoor air by active sampling and thermal 
desorption-gas chromatography-mass spectrometry. Talanta, 82 (3): 1230-1239. doi: 10.1016/j.talanta.2010.06.044.

Montgomery ER, Edmanson AL, Cook SC, Hovsepian PK. 2001. Development and validation of a reverse-phase HPLC method for analysis of efavirenz and its related substances in the drug substance and in a capsule formulation. J. Pharm. Biomed. Anal., 25: 267-284. DOI: 10.1016/s07317085(00)00495-7.

Mottier N, Tharin M, Cluse C, Crudo JR, Gómez Lueso M, Goujon-Ginglinger CG, Jaquier A, Mitova MI, Rouget EGR, Schaller M, Solioz J. 2016. Validation of selected analytical methods using accuracy profiles to assess their impact of a Tobacco Heating System on indoor air quality. Talanta, 158: 165-178.

DOI: 10.1016/j.talanta.2016.05.022.

Pathade P, Imran M, Bairagi V, Ahire Y. 2011. Development and Validation of Stability Indicating UV Spectrophotometric Method for the Estimation of Sitagliptin Phosphate in Bulk and Tablet Dosage Form. J. Pharm. Res., 4(3): 871-873. DOI: JPRS-PA0000692.

Pinguet I. 2015. Validation analytique : Application de la procédure SFSTP 20032006 au domaine de la phytothérapie. PharmD Thesis, Université de Bordeaux, Bordeaux, p. 92.

République Togolaise, Ministère de la santé et de la Protection sociale. Programme National de Lutte contre le SIDA et les IST (PNLS), p. 61.

Safari M, Shamsipur M, Zohrabi P, Ebrahimzadeh H. 2019. Solid-phase extraction combined with dispersive liquidliquid microextraction/HPLC-UV as a sensitive and efficient method forextraction, pre-concentration and simultaneous determination of antiretroviral drugs nevirapine, efavirenz and nelfinavir in pharmaceutical formulations and biological samples. $J$. Pharm. Biomed. Anal., 166: 95-104. DOI: 10.1016/j.jpba.2019.01.003.
Sarr SO, Diop EHA, Diop A, Atoun AGS, Ndiaye SM, Waffo Tchounga CA, Gueye R, Thiam K, Wane TM, Sarr A, Ndiaye B, Rudaz S, Diop YM. 2016. Development and Validation of a Capillary Electrophoresis Method for Quality Assessment of Metronidazole-based Drugs. IJMASS, 5(1): 1-11.

Smith F, Augsburger M, Varlet V. 2014. Accuracy Profile Validation of a New Analytical Method for Propane Measurement Using Headspace-Gas Chromatography-Mass Spectrometry. $J$. Anal. Toxicol., 38:73-79. DOI: 10.1093/jat/bkt098.

Tibalinda P, Sempombe J, Shedafa R, Masota N, Pius D, Temu M, Kaale E. 2017. Formulation development and optimization of Lamivudine $300 \mathrm{mg}$ and Tenofovir Disoproxil Fumarate (TDF) 300 mg FDC tablets by D-optimal mixture design. Heliyon, 3: e00207. DOI: 10.1016/j.heliyon.2016. e00207.

Tittikpina NK, Agban A, Gbogbo KA, Hoekou YP, Pereki H, Batawila K, Akpagana K. 2013. Évaluation des propriétés antimicrobiennes de Pterocarpus erinaceus Poir (Faboïdeae) et Daniellia oliveri (Rolfe) Hutch. et Dalz (Caesalpinoïdeae), utilisées en médecine traditionnelle au Togo. Int. J. Biol. Chem. Sci., 7: 15861594.

United States Pharmacopeia (USP). 2013. National Formulary (NF) / USP $36-N F$ 31, Volume 2. United States Pharmacopeial Convention: Rockville, Md.

WHO. 2017. News release of the $28^{\text {th }}$ November 2017 on falsified medical products. WHO: Geneva.

WHO. 2018. Facts sheet on Hepatitis B. WHO: Geneva.

WHO. 2019. Ref. EMP/SAV/Alert $N^{\circ}$ 5. Medical Product Alert $N^{\circ} 5 / 2019$ - Falsified meningitis vaccines circulating in Niger. WHO: Geneva. 